\title{
Designing a Sustainable House in Kuwait
}

\author{
Yousef Abdul Mohsen Al-Haroun \\ College of Architecture, Kuwait University, Shuwaikh 70654, Kuwait City, Kuwait
}

Received March 22, 2021; Revised April 20, 2021; Accepted May 28, 2021

\section{Cite This Paper in the following Citation Styles}

(a): [1] Yousef Abdul Mohsen Al-Haroun , "Designing a Sustainable House in Kuwait," Civil Engineering and Architecture, Vol. 9, No. 4, pp. 1012 - 1025, 2021. DOI: 10.13189/cea.2021.090405.

(b): Yousef Abdul Mohsen Al-Haroun (2021). Designing a Sustainable House in Kuwait. Civil Engineering and Architecture, 9(4), 1012 - 1025. DOI: 10.13189/cea.2021.090405.

Copyright $(2021$ by authors, all rights reserved. Authors agree that this article remains permanently open access under the terms of the Creative Commons Attribution License 4.0 International License

\begin{abstract}
This paper discusses the process of designing a sustainable house in Kuwait. The design concept uses Kuwait's traditional vernacular elements as the primary sustainable strategies with priority given to cutting energy costs, using passive solar systems, solar panels and alternative air conditioning. The method used in this study is a variant of the "research through design" approach. This paper describes a viewpoint rarely discussed and addresses the many challenges of sustainable design and its implications for the larger built environment and society in Kuwait. The paper contends that although designing a house to express culture and promote sustainability is possible there are significant barriers within the current construction climate. There is no motivation or incentive for homeowners to design their houses sustainably due to the availability of cheap subsidized energy and water supply. Moreover, sustainable materials and technology are difficult to access in Kuwait due to low demand and high cost. There is a significant gap between ideal sustainable design and the reality of construction. Therefore, the paper asserts that the government needs to play an active role in terms of building eco-regulations, planning, and policy-making to establish sustainability as a mandatory part of design and building practices.
\end{abstract}

Keywords Kuwait, Sustainability, Vernacular, House, Research through Design

\section{Introduction}

A recent UN fifth assessment report about the science of climate change concluded that climate change is real and human activities are the main cause [1]. The UN continues to assert that unless action is taken by the global community, an increase in global warming will have severe consequence such as shifting weather patterns that threaten food production and rising sea levels that would increase the risk of catastrophic flooding [1]. Furthermore, according to a recent study, Kuwait, after Qatar, has the largest ecological footprint in the world [2]. Kuwait's Ministry of Electricity and Water ranks Kuwait the first in the world in the consumption of water and electricity [3]. Every year there is an $8 \%$ increase in Kuwait's electric load compared to the $2 \%$ international average [3]. Therefore, Kuwait's transition towards sustainable development is of crucial and urgent importance.

Hence, this research by design project attempts to use vernacular practices as a bridge towards sustainability and reduce the load on the nation's electric grid. Prior research discussed people's attitudes and perceptions of traditional vernacular elements in Kuwaiti houses [4]. It revealed fascinating contradictions and disconnects in socio-cultural understanding between participants, reflecting the disunity between past and present built environments and further highlights the larger effects of modernization. This has been revealed by people's preference of the modern villa despite their appreciation of the vernacular. It also shows the changes in their perceptions regarding what is important for them in their houses and their relationship with social practices. Such studies help understand how people deal with and adapt to the collision between traditional concepts and modernity. For example, how the courtyard has been replaced by the family living room [4].

This design-built initiative aims to further enrich the findings of the past studies via a research through design 
approach. The design of the house becomes a vehicle to understand how to use Kuwaiti vernacular elements as precedents for sustainable design. How can an architect design and build a contemporary vernacular house in Kuwait as means to promote and direct sustainability? How can traditional elements be used or not in a modern villa? And what are the various implications and challenges that such a project may face? It is not the intention of this study to in any way assert that this is the only way to design with reference to culture. On the contrary, this experiment aims to generate discussion and dialogue between researchers and designers in order to bridge the gap between theory and practice.

The paper starts by discussing relevant literature, which provides insights into the larger theoretical framework of the study. It then discusses the method using the research through design approach, and afterwards presents the design, from concept and sustainable strategies, to the final product. Subsequent sections describe the process of governmental approvals and construction. Before the conclusion, critical design and construction observations and recommendations for direct future sustainable design inspired from the vernacular are reflected upon.

\section{Literature Review}

Throughout the second half of the $20^{\text {th }}$ century, the thrust of modernity through globalization has contributed to massive environmental degradation. This has been regarded as a universal problem with the potential to threaten the very existence of modern civilization. Recognizing the damaging nature of human activity has been vital in slowing down the environmental impact and its future consequences on our planet. As concern over environmental issues grew stronger and vocal, a new approach to environment and development took shape, out of which the concepts of sustainability and sustainable development emerged. The literature for this study will focus specifically on how to use culture as means to promote sustainable initiatives. The United Nations Environment Program suggests that local factors need to be taken into account, "with attention given to the adequate and rational use of the natural resources and to appreciation of technological styles (innovation and assimilation) and organizational forms that respect the natural ecosystems and local socio-cultural patterns" [5]. Without a socio-cultural support framework, sustainable development may be challenging to achieve. People need motives and incentives to think and act sustainably, and therefore, culture may be the answer to promote a more sustainable way of life.

\subsection{Cultural Sustainability}

As part of the larger movement of sustainability, cultural sustainability has increasingly been recognized as another approach to countering the far-reaching effects of modernization and globalization. It is an interdisciplinary concept that aims to promote the significance of culture through sustainable development. Culture is a key dimension in sustainability [6] and it is important to recognize its impact on providing local solutions to global challenges. Moreover, the value in linking cultural and ecological sustainability provides for a better foundation to implement successful sustainable development [7]. Some researchers have also used the term "social" when incorporating notions of "culture" or cultural issues in society. Gleeson et al. asserts that sustainable development "is about the achievement on a global scale of three principles: economic development, social justice and ecological responsibility" [8].

Alongside social, economic and environmental sustainability, Hawkes calls culture the "fourth pillar of sustainability" [9]. His description encompasses a wide range of human behaviour that embodies and expresses the values of a society. Hawkes argues that it is these values of culture that are instrumental in driving and reconfiguring government policy towards sustainability. In order to achieve a sustainable and healthy society he suggests that a cultural framework is needed in parallel with social, economic, and environmental frameworks [9]. Hawkes explains how everything that is built in society is an extension of its social values and it is through society's values and an expression of its culture. Therefore, the "application of culture" is integral for new paradigms that emphasize sustainability and well-being: "without a foundation that expressly includes culture, the new frameworks are bereft of the means of comprehending, let alone implementing, the changes they promote. Culture has to be a separate and "distinct" reference point" [9].

\subsection{Towards a Contemporary Vernacular}

Until recently, the "vernacular" has been largely ignored in architectural discourse. Architectural history has been more focused on monuments designed by architects. In fact, vernacular architecture had been referred to as "primitive" or "folk" by researchers around the middle of the twentieth century [10][11]. The first reference to the word "vernacular" was in 1861 by Petit [12] and it has been used very broadly ever since. In architecture, the term "vernacular" came to refer to indigenous or traditional that covers an immense range of building types, forms, traditions, uses, and contexts [13]. All forms of vernacular are built to meet specific needs, accommodating the values, economies, and ways of living of the cultures that produce them [14]. Fathy believed that true vernacular came from a "living tradition" and it was not about style. It was the essence of the traditional that Fathy wanted to revive in buildings through local 
materials and light construction to bring back quality to the things that were paramount in people's everyday life [15].

Rapoport sees vernacular as an environment that has not been controlled by a designer [16]. He asserts that building a house is a "cultural phenomenon" and its form and organization are influenced by its culture [16]. However, in later years in his quest to redefine the term Rapoport acknowledged that there are many implicit definitions. In his paper Defining Vernacular Design, he attempts to redefine vernacular using a scale of three styles within the vernacular that depend on the characteristics of the building, the vernacular itself, primitive high style, and popular style [17]. On the other hand, Turan understood vernacular architecture as a practical activity following environmental adequacy rather than knowledge; it is a way of acting within the conditions of existence, in order to fulfil certain environmental needs for a particular group of people [18].

Richards presents two ways to conceptualize "vernacular", the first is "descriptive and pragmatic..." which sees architects and anthropologists "who want to understand and preserve vernacular structures for their own aesthetic, historical and technical merits and to find out how they might be adapted for future building practices" [19]. The second is "prescriptive and idealistic" which may be seen in the works of architects, historians, and theorists as "a renewal of Modernist vows in vernacular vestments" [19]. Richards closely focuses on the second understanding and explores how the "vernacular was being forwarded as an antidote to the perceived wrongs of Modernism" [19].

Many early architects of the modern movement acknowledged how vernacular forms may have significance for modern architects. In his Introduction of philosophy of architecture Frank Lloyd Wright wrote about the "spiritual lessons that the East has to teach the West" [20]. Le Corbusier was fascinated by the vernacular mud-brick houses of Algeria. He described them as "a centre of happiness, of serenity...founded upon the solid rock of fundamental truth. This city exists to serve mankind, to serve both body and soul" [21]. Other architects such as Alvaro Siza and Jorn Utzon also used culture in varying degrees to produce contemporary expressions.

Today in an increasingly globalized world and the constant shaping and making of the built environment there comes the desire to preserve local culture and identity. The challenge is to make a "new or contemporary vernacular architecture" which is as Richardson puts it, "to reflect by analogous inspiration the characteristics of local buildings, their scale in particular... to concentrate on the use of materials, the landscape, the local culture or even no more than the idea of continuity with past" [22]. A contemporary vernacular is described as a "commitment to uncover a particular tradition's unique responses to spatial arrangements, place and climate and thereafter exteriorize these established and symbolic identities into creative forms" [23].

In his book Architecture Without Architects, Rudofsky advocated understanding and learning from vernacular societies that may revive "the art of living in buildings" [24]. Rudofsky suggested that the insights architects gain from non-architect-designed or vernacular landscapes might guide them to lead a movement for new designs [24]. In fact, it has been suggested that the preservation of tradition and specifically residential forms may also be essential for the preservation of cultures [25]. This is further evident with Pearson, who writes "much misunderstanding of the past stems from our lack of information, so many indigenous cultures and traditions have disappeared from the link with knowledge and values formally passed down from generation to generation has been broken. The demise of vernacular building is part of this general process" [26].

Furthermore, Paul Oliver's paper Vernacular Know-How highlights the effects of modernization and specifically how it relates to vernacular buildings. He stresses that, "We have witnessed the thoughtless destruction of many traditional buildings... we know that inappropriate housing has been mindlessly inflicted upon countless numbers of people in the name of modernity" [27]. The effects of modernization and globalization evident throughout built environments around the world are taking local societies away from their vernacular expression and sustainable living. However, there are an increasing number of architects worldwide that are committed to a cultural and environmental response within their local contexts. It is a response that aims to balance the natural environment, cultural significance, and the ever changing social and economic needs of society [28][29].

\subsection{Regional Discussions}

In Kuwait, despite the recognition by many architects to create a new vernacular form, no significant changes have been made to date. There seems to be a lack of research to further understand this phenomenon, and therefore, find ways to overcome any obstacles to assimilate the old with new. Similar desires are evident throughout the Arab world. These phenomena have produced a clash of styles in the built environment with no clear cultural identity and environmentally unsustainable structures.

Some architects have used vernacular elements as aesthetic features in their designs. However, there is a growing consensus among designers that the understanding and application of these elements needs to go beyond abstraction and embellishment. These elements represent the harmony and coming together of cultural and 
environmental conditions in old Kuwait City. The idea is not to replicate the past but learn from it and enhance these elements through new technologies to express a new form of contemporary vernacular.

In Saudi Arabia, many architects have highlighted the effects of rapid development and modernization. AlHemaidi (2001) highlighted the metamorphosis of Riyadh's urban fabric. He argues how imported forms and regulations did not relate to the built environment, culture, and climate, which in turn resulted in significant cultural issues [30]. AlNaim sees architects' increasing awareness of cultural issues as a form of "cultural resistance" [31]. In his book Architecture and Culture: Critical Studies of Arab Architecture, AlNaim argues that the rapid urbanization in the Arab world has produced two main divisions; the first group rejects historical heritage, the second considers the past as the only valid evidence and should be used in today's buildings [31].

Saleh also from Saudi Arabia, presented a study that analysed integration of tradition and modernity. He asserts that climatic, social, topographic and economic aspects are all important factors to create a regionalism [32]. This further reveals the need to not clash but merge various environmental, social, and economic frameworks to achieve a successful contemporary vernacular. In Oman, Taylor et al. studied environmental advantages of vernacular architecture for contemporary design. They highlighted how traditional passive cooling techniques in contemporary buildings present a significant opportunity for energy saving [33].

In the UAE, many initiatives are underway to use sustainable design as means to improve people's quality of life. The Estidama (which means sustainability in Arabic) Guidelines in Abu Dhabi have contributed to discussion of how to create more sustainable communities, cities, and global enterprises [34]. A manifestation of this policy is Masder City, an eco-city that brings together green companies from around the world to collaborate on the advancement and innovation of green technologies. Furthermore, the Dubai Municipality recently made it mandatory for private sector buildings to follow their new Green Building Regulations. These regional initiatives by the UAE are some of the earliest that require all buildings to follow green regulation and may become a model for the region and world. On another front, researchers in the UAE University of AlAin presented a study in 2012 with a holistic approach to designing a sustainable house in the desert of Abu Dhabi. It reported that the design achieved significant enhancement over the typical Emirati house case; $59 \%$ reduction in the greenhouse gas emissions and the utility bill [34].

Although the study was commendable, it focused mainly on the environmental efficiency of the building. However, it is essential to understand the homeowner's attitudes and perceptions about a sustainable house.
Deleted sentence. This has been highlighted by Al-Haroun's (2015) study, which points out, that although people desire traditional sustainable elements in their houses, there are many barriers to using them. It argues that without a fundamental change in government policy and regulations to create incentives for homeowners, a sustainable built environment may not be possible [35]. The proposed study intends to build upon prior research and fill gaps in the literature by using a research through design approach to construct an eco-villa in Kuwait.

\section{Methodology}

The method used for this study is research through design, which is similar but slightly different from "research by design." It is a practice-based inquiry where the design process and final product become a source of new knowledge. Although, this concept has been used for centuries in the form of experimentation and trial-and-error to develop design [36], its role and value in architectural research has only recently gained acceptance and recognition. It is a dynamic and evolving concept in an academic context [36]. Research through design or RtD was a term coined by Frayling in 1993. He described RtD as a particular way of thinking to gain a particular approach to knowledge to understand certain things that are outside of design [37].

Some researchers see research through design as a design inquiry that produces an artifact with the intended goal of societal change [38][39][40]. Zimmerman and Forlizzi define it as an "approach to conducting scholarly research that employs the methods, practices, and processes of design practice with the intention of generating new knowledge" [41]. It is the process of "iteratively designing artifacts as a creative way of investigating what a potential future might be" [42]. It uses trial and error to constantly develop projects in the real world [43].

There is a fine line between the two design research methods in architecture. Research by design, is defined as research in which design is explored as a method of inquiry. This is usually through the development of a project in which different mediums such as, sketches and mapping are used. Others see research by design as gaining experience from practice and its process of designing as pillars of research [44]. The design frames and guides the methods, data collection, and results of the study. Thus, both the approaches- research by and through design are valuable in gaining new insights and knowledge, which may have a tangible impact on people's quality of life [45].

\subsection{Application of Research through Design}

The method has been conducted in this study by first 
carrying out a complete literature review about the sustainability and vernacular architecture. Further, the study uses prior studies to direct a link between theory and practice. Then the process of design empowers the researcher to explore multiple paths towards sustainability using the vernacular in Kuwaiti houses. Knowledge gained in the process expands existing knowledge, which in turn enriches discussions between theory and practice. The process of research is itself sometimes considered more important than the product. It is through the architect's design, design experiences, data collection and application of strategies that new understanding is generated and transformed into knowledge [46]. In research by design, the practitioner becomes a "practitioner-researcher" [47].

The proposal specifically uses Kuwait's traditional vernacular elements as means to promote sustainability. The elements have been used as a vehicle in design to explore the potential of reintroducing sustainable principles back into Kuwait's domestic built environment. After the design and construction of the eco villa, a post occupancy evaluation and building survey would indicate to what extent the house is sustainable. Important questions such as: Did the solar panels significantly reduce electricity costs? Did the bagdir or windcatcher work as designed? Did the courtyard provide the desired microclimate shielding the house from heat in summer? To what extent do the materials used in the house promote sustainability and reduce the carbon footprint? These questions would all be answered by transferring new knowledge from practice to theory. The intention is that these ideas would enrich the literature; spark much needed discussion, and guide future sustainable design projects. It may be fair to say that a research through design project is never really complete, always evolving, an iterative cycle that builds on past studies while experimenting with new ideas. Figure (1) presents the research through design process showing the four main stages of the study. 


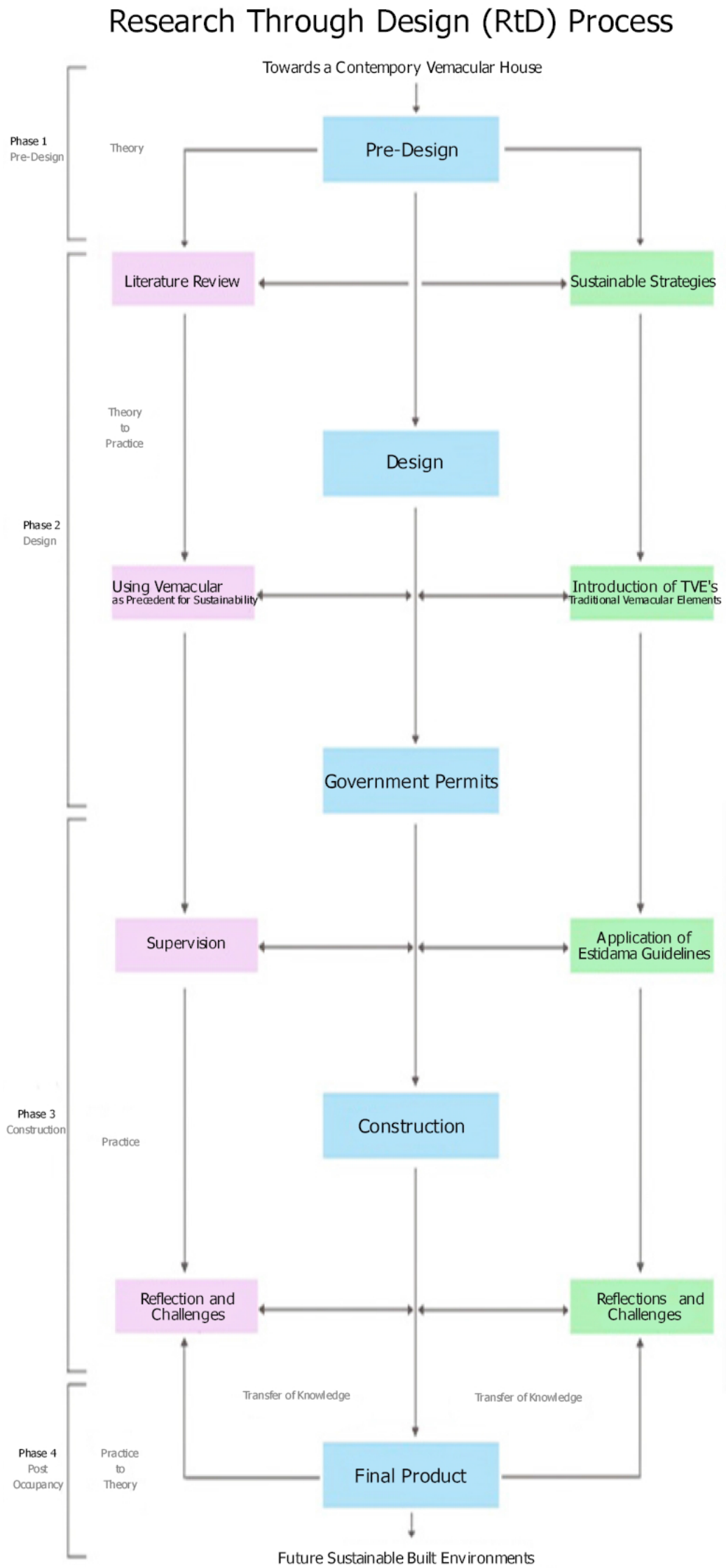

Figure 1. Research through design process diagram: It shows the researcher's theoretical framework, from theory to practice through four main phases. Source: The Author: 2020. 


\section{Results}

\subsection{Design Concept}

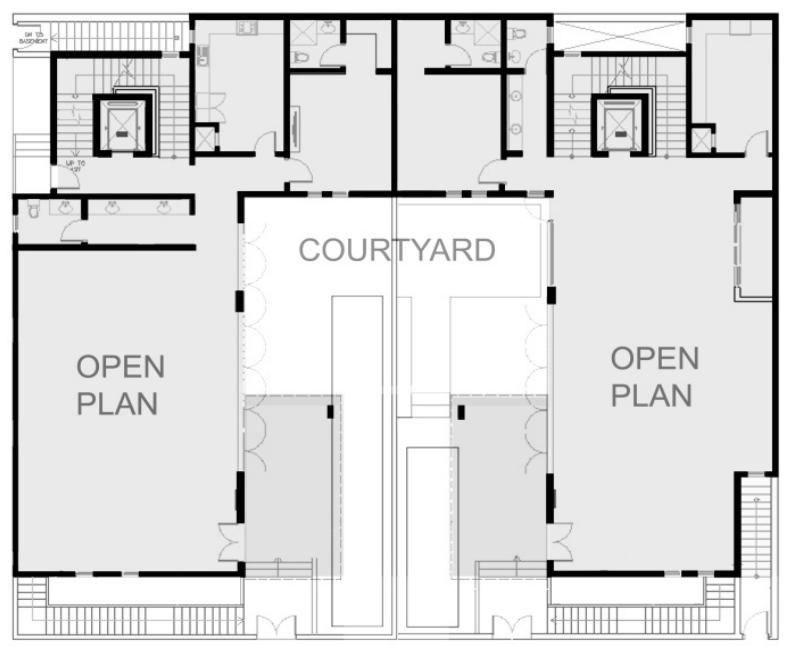

GROUND FLOOR

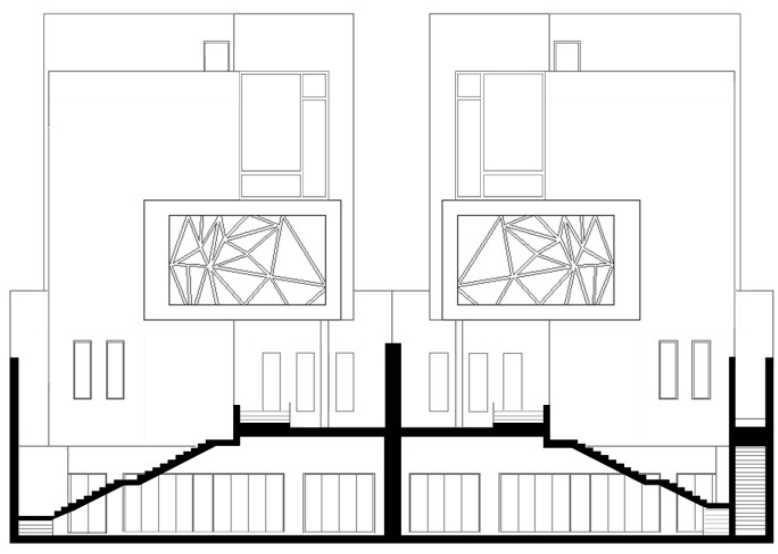

SOUTH ELEVATION

Figure 2. The top image is the floor plan of the two houses that together form the central courtyard. Each house is $15 \mathrm{~m}$ wide by 25 meters in length totalling 375 square meters. The bottom image is the main south sectional elevation of the house. Notice the connection between the main courtyard in the ground floor and sunken courtyard in the basement. Source: The Author: 2020

The concept of this design uses Kuwait's traditional vernacular elements as means to promote sustainability. Specifically, it uses the courtyard, the liwan (shaded corridor), bagdir (windcatcher), and diwaniya (traditional men's reception). The elements were chosen after referring to AlHaroun (2015) which found them to be the most well-known and desired by the participants, suggesting a higher probability of their use [48].
Two twin villas share a central courtyard. The courtyard not only references the vernacular but also seeks to resume its traditional functional role of strengthening family relationships. To reinterpret this concept within today's postmodern world, the architect uses a garden, waterfall, and swimming pool (See Figure 2). These contemporary amenities are also used to create a micro-climate and reduce the heat. The courtyard is enclosed from all sides except the street side. The idea is to have a feeling of enclosure and at the same time remain connected to the outside. This connection is a modern notion [49]. It is an attempt by the architect to build a bridge between past and present house forms. The implications of this feature will be discussed in the "reflections" section of this paper.

The design uses an "open plan" concept, meaning all the main spatial components of the house are left open, overlooking the courtyard, to be adjusted as and when needed by the homeowner. This was done to allow for personal expression. Moreover, Rapaport advocates for, "open-ended" design in housing to enable homeowners to play an active part in designing their living spaces [50]. Similarly, John Turner asserts that self-built housing provides opportunities for expressions of personal and social identity [51].

\subsection{Sustainable Strategies}

This segment introduces how the research through design study method facilitated exploration of concepts and ideas for building a sustainable house. Figure (3) below presents the evolution of the conceptual design phase.

\subsection{Traditional Vernacular Elements}

\section{Courtyard}

In Kuwait, the courtyard house was one of the most important elements that made up the urban fabric of the old City. The harsh desert environment and religious values encouraged the development of this innovative architectural concept. Thus, the courtyard house emerged, which maintained a delicate balance between culture and sustainable resourceful living, reflecting awareness and sensitivity towards the natural world. The courtyard functioned as a protective capsule against the climate, by repelling heat and sandstorms to the minimum, and properly located slits for ventilation [52]. 


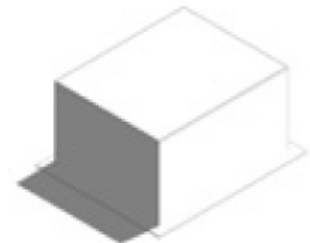

1 Modem Block Villa

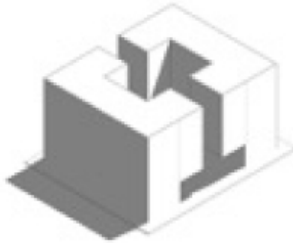

4 Hybrid Liwan

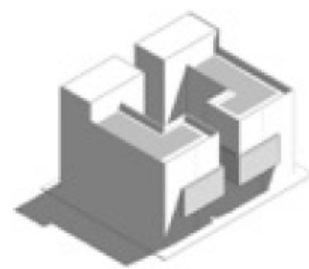

7 Green Roof

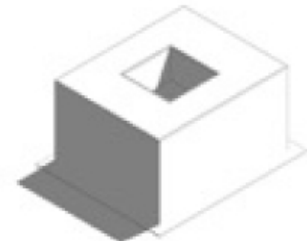

2 Introduction of Countyard

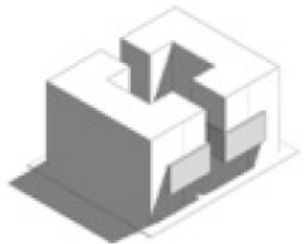

5 Modem Mashrabiya

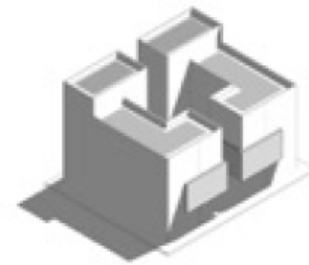

8 Photovoltaic Solar Panels

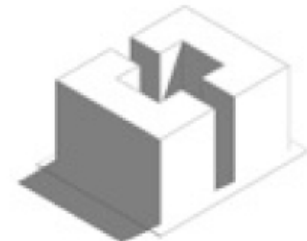

3 Countyard Development

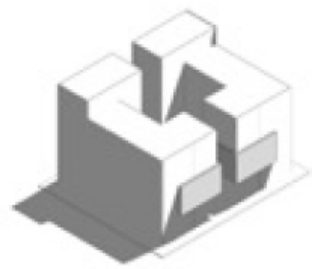

6 Bagdir as Stair well

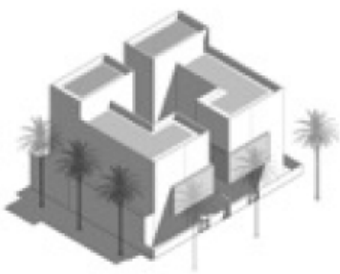

9 Sustainable Landscape

Introduction of Sustainable Vernacular Strategies through Design Iterations

Figure 3. The above diagram represents the iterative research through design process. It goes through many phases of experimentation while adding traditional vernacular elements in the house. Each element is carefully designed and placed to meet functional and aesthetic contemporary needs. Source: The Author: 2020

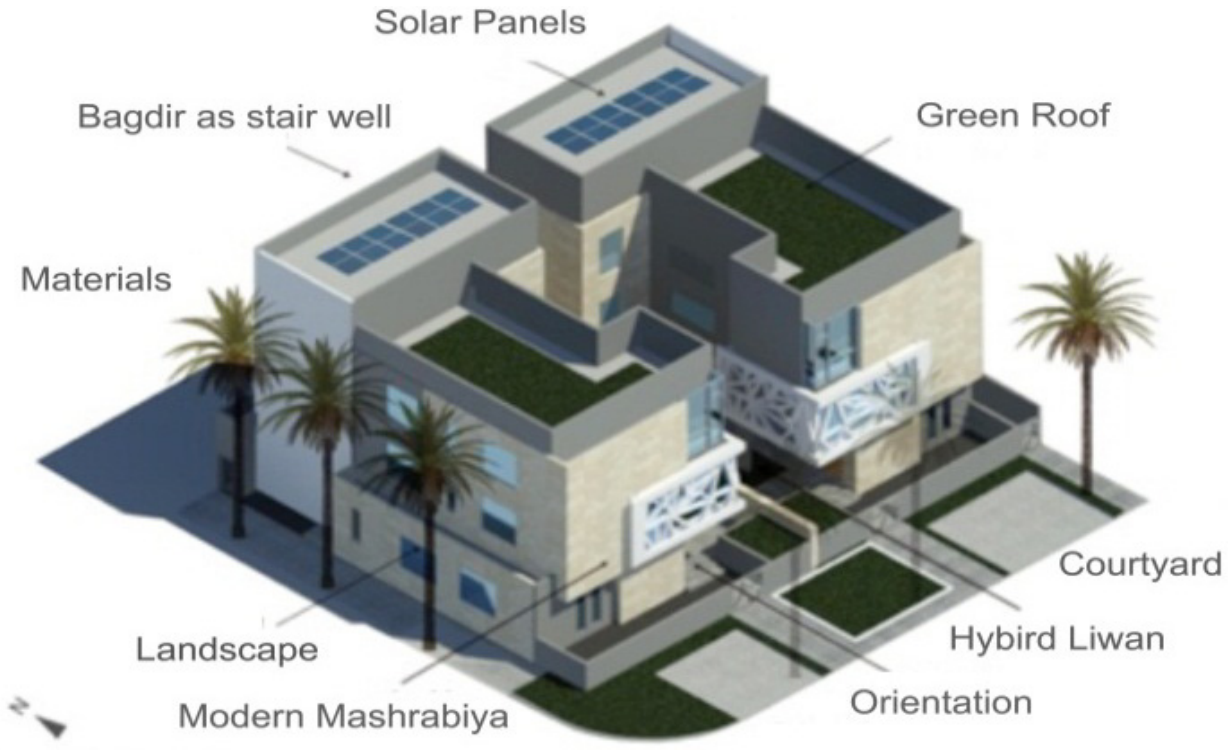

\section{SUSTAINABLE STRATEGIES}

Figure 4. The proposed house design and sustainable strategies using traditional vernacular elements and Estidama guidelines. Source: The Author: 
Therefore, it is very clear that the courtyard carries a historical significance. It is also very much desired in Kuwait despite the above-mentioned misconceptions. Thus, it is an integral part of the proposed design-built project. The house has two courtyards: one at the ground floor and the other a sunken courtyard in the basement. Figure (5) shows the importance of the courtyard in terms of providing shade to the house during the summer solstice, when the sun is at its highest in the year.

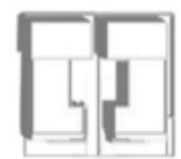

$11 \mathrm{am}$

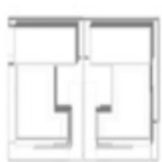

$12 \mathrm{pm}$

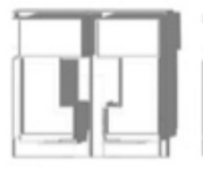

$1 \mathrm{pm}$

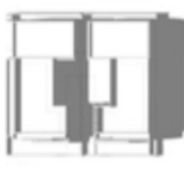

$2 \mathrm{pm}$
Figure 5. Solar sun path during peak daylight hours on the summer solstice. Source: The Author: 2020.

\section{Hybird Liwan}

A liwan or loggia is a covered walkway that separates the courtyard with some rooms of the house. The liwan would also provide a form of protection for some rooms from direct sunlight. It would be used alongside the courtyard as a place where the family would gather and socialize. In this design proposal, the liwan has been used differently- it is the space between the street and courtyard. Although covered, it only has one column that carries an overhanging mashrabiya (traditional sun shading device). The space overlooks a small garden and swimming pool with outdoor seating.

\section{Sunken Diwaniya}

In Kuwait, the diwaniya is a space in the house where men would gather and socialize. It has its roots in Kuwait's traditional courtyard house and has managed to survive modernization. Many researchers have discussed this phenomenon [53][54][55]. It was and still is an important place in Kuwaiti society. However, for this particular house design, instead of facing the street, the diwaniya has been taken to a sunken courtyard in the basement. There are several reasons for this decision. First, the front façade of the house overlooking the street was only 15 square meters, which is not enough to also accommodate the courtyard, garden, entrance, and guest reception. Second, the diwaniya was intended for family and close friends, rather than general visitors, and therefore, the basement takes it to a more private realm. Third, the design intended to minimize energy costs of the diwaniya by using the environmental cooling benefits of a sunken courtyard [56].

\section{The Stair Well as Bagdir}

The bagdir or windcatcher is a clear example of an architectural feature within the courtyard house that is designed to suit the climactic conditions. It is a mud-brick shaft that rises above the courtyard house with an opening facing prevailing winds. It then funnels the air down to a level that allows the breeze to reach a seated or sleeping person directly. Today, instead of sustainable materials or the cooling badgir, people turned to technology to solve their problems. Some see technology as a form of luxury; they have air conditioning and do not need a courtyard or bagdir anymore for natural ventilation. After gaining wealth people want something different that does not remind them of the poorer days; this change is not always better.

In this house, the stair well becomes the bagdir or wind catch. The stair block has been placed in the north façade of the house in order to capture the cool north prevailing winds and direct them through the main living spaces. The windows have been designed as louvers to control wind speed and direction inside the house. Although, this contemporary windcatcher does not look like its predecessor, it has similar functions and ventilating qualities. Figure (6) demonstrates this process through a section of the house stair well. The design attempted to transform the traditional bagdir into a modern contemporary version without much effort. The high-rise, volume, and shape of the stair well make it the ideal space to apply this concept. 


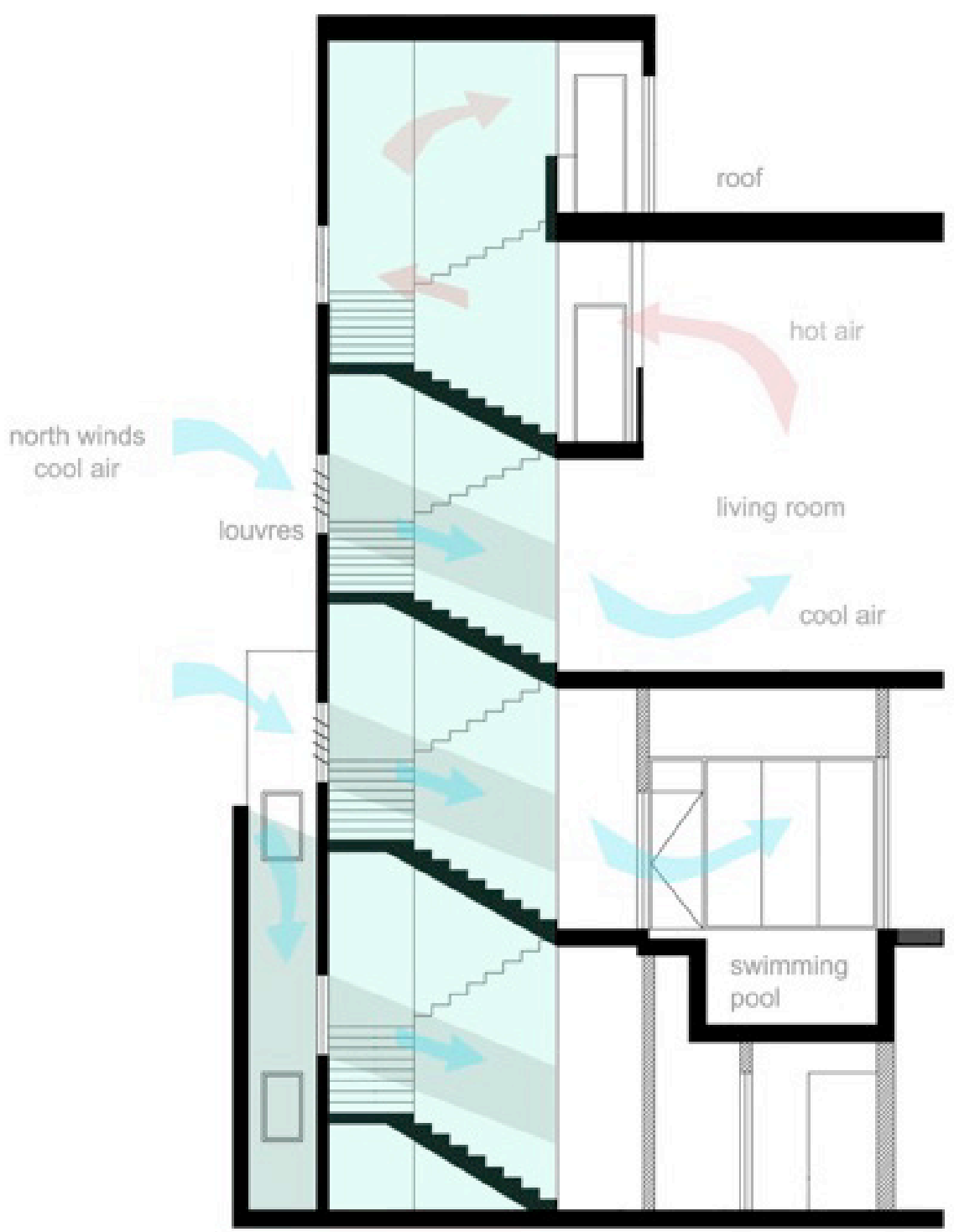

\section{Bagdir as stair well section}

Figure 6. The section shows the bagdir reinterpreted as a stair well in the house. It funnels cool north air into the interiors ventilating the living spaces. The hot air then rises and through a double ceiling atrium is rechanneled to the roof. Source: The Author: 2020 .

\section{Other Elements}

\section{Modern Mashrabiya}

The design also uses a modern mashrabiya. Historically, this element is not from Kuwait's vernacular; rather, it's a regional element found mostly in Saudi Arabia, Egypt, Palestine and Syria. The intention here is to further enhance the design by introducing a purely Islamic element however with a contemporary interpretation. An overhanging modern mashrabiya structure sits directly above the courtyard space shielding the house from the harsh south façade where temperatures in the summer may reach over 50 degrees Celsius. What is a modern mashrabiya? The architect has coined this term. It is defined as a sun-screening device inspired by tradition in function but different in form and materials. For this proposal after numerous iterations and experimentations, the proposed modern mashrabiya was given contemporary geometric shapes.

\section{Green Roof/Garden}

In the past, people in Kuwait's traditional courtyard houses used to sleep on their rooftops, especially during hot summer nights. They would relax and enjoy the cool breezes from the Arabian Gulf. This experience disappeared with the advent of the concrete modern villa and air conditioning. The current proposed house design intends to reintroduce the roof space back into the Kuwaiti house. It does this through a green roof. Green roof, roof garden, or living roof as they are also called is all spaces that have plants and vegetation with a waterproof membrane. 


\subsection{Sustainable Materials}

Kuwait exports oil and imports almost all its consumer goods and industrial materials. Despite importing raw materials, it has robust industries manufacturing structural materials such as steel, concrete, concrete blocks, aluminum, terrazzo, sandstones and glass. Kuwait's construction industry is very much dependent on international trade and commerce. This is not something new; in the pre-oil era, Kuwaitis used to import wood and other building materials from Zanzibar and India. However, today due to low demand and high cost, sustainable materials and technology are not easily accessible in Kuwait. The architect struggled with the idea of notion of importing goods, as it would involve additional transportation and energy costs, going against many sustainable principles. Despite this ethical dilemma, few local or regional materials were used in the construction phase.

All efforts were made to use local sustainable materials to minimize environmental impact. Concrete and particularly precast concrete slabs were used in some areas of the eco villa. Using concrete is an excellent way of controlling heat within a building and it is also affordable as a building material [57]. It is very sustainable in terms of energy usage and production time. [51]. In addition bamboo panels have been used in the interiors. Bamboo is a very eco-friendly building material and has an incredibly high regeneration rate [58].

Limestone stone was used for three reasons: 1) Insulation, 2) It's refined beige texture provided the perfect camouflage for sand deposited on the external walls during sandstorms. Many people clean their houses with water after sandstorms, which is a very unsustainable practice in the desert. Using a sand-like color reduces the maintenance effort of the house façade, because if they cannot easily notice the sand they are less likely to clean it. 3) Third, was aesthetics. The architect used natural stone in the outside and inside of the house to create a sophisticated warm and positive vibe. Thus in case limestone the benefits outweighed the additional transportation costs.

\subsection{Estidama Principles}

Along with the above elements the design uses Estidama, the Pearl Rating System from Abu Dhabi Planning Council as another guide to further implement sustainable strategies. It was selected due to its focus on regional applications for hot desert climates as opposed to LEED and BREEAM guidelines. Although the following strategies have been inspired from the Estidama guidelines [59], they have been modified and developed for this project in Kuwait.

1) Orientation: To maximize natural lighting and minimize solar gain

2) Passive solar systems to minimize heat gain: By increasing depth of window recess to allow for louvers systems and a mashrabiya
3) Reduce energy: Using new technology by adding solar panels and alternative air conditioning and elevator. In addition to insulation materials and other systems, priority has been given to cutting energy costs, ultimately aiming to reduce dependency on the state's electric grid.

4) Minimize water loss: By designing water efficient landscapes using local plants and trees

5) Outside Space: Creating a microclimate with comfortable outdoor spaces

6) Green roof: A planted roof is used to insulate the house to reflect solar gain into the atmosphere

\section{Discussion}

This section discusses a few reflections that have emerged from the architect's experiences of designing a sustainable house in Kuwait. These thoughts are a direct product of using research through design as the study's methodology. They highlight the benefits of this approach as well as the limitations, especially in relation to the application of sustainable strategies. The architect aimed to design a sustainable house using traditional vernacular elements. So, was this goal accomplished? And is the house culturally and environmentally sustainable according to international rating standards? Although vernacular elements such as the courtyard, bagdir, and diwaniya were used, it does not necessarily make the house sustainable. However, the design project did use Estidama guidelines and other sustainable strategies.

Research through design is a great platform for experimentation, gaining new knowledge and exploring new ways of doing things. Moreover, learning through trail-and-error significantly improves future design proposals. The skills gained stay for life and allow the architect to excel in his or her field and be better prepared for future endeavours. It may be difficult to assess how sustainable the house is at this time. With regards to culture, a post-occupancy investigation and other surveys are needed to determine homeowners' perceptions and attitudes towards such designs, juxtaposed with classical, modern, and other styles. A complete post occupancy evaluation and building survey is a critical part of the research through design process. However, it can be carried out only after the homeowners live and experience vernacular elements used in the house and report to what extent they achieved sustainability. From that data new future design iterations may emerge to improve the design and complete the cycle, feeding back into the literature.

Environmentally, the courtyard is shaped into a nice enclosed outdoor space open to the sky, while the bagdir as part of the stair well channels the prevailing winds, ventilating the interior spaces. The mashrabiya blocks harsh sunlight in the south façade. Questions were raised as to why place a corner glass curtain wall above the mashrabiya as this will increase solar gain. The architect intended to add a purely modern element within the 
façade to also demonstrate that using new technology and more glass does not necessarily mean more solar gain. Double-glazed low-E heat reflective glass has been installed for all the skylights, curtain walls, and windows of the house. New air conditioning technology uses environment friendly gas, and elevator technology relies on less energy. In addition, solar panels were used to minimize electricity costs. All the light fixtures are LED lighting systems, which use less energy and last much longer than conventional lights. Several recycled and sustainable materials have also been used in different floorings and wall finishes. What most of these strategies have in common is that they decrease solar gain or prevent heat from entering the house, thereby reducing the need for air conditioning and allowing maximum use of natural ventilation. Therefore, less carbon dioxide will be released in the atmosphere and a reduction in energy translates to less electric costs. If people in Kuwait realize and understand this concept perhaps more homeowners will be motivated to use sustainable strategies in their homes. But unfortunately, cheap subsidized energy from the government makes people less willing to take action.

There were a few challenges in this design-built project. In terms of design, the research through design method provided the opportunity to explore and develop the potential of new practices for cultivating and enhancing sustainability in Kuwaiti houses. Although this approach proved to be productive in terms of its contribution to the discourse on sustainability, its effectiveness in the larger society is yet to be seen. Therefore, more design research is required to further understand the impact of introducing these concepts in reality.

\section{Recommendations}

After employing research through design as the study method and experiencing the design-built of a sustainable house, the architect has three recommendations for researchers and practitioners in the field.

(1) The need for government eco-regulation: There is a "lack of vision" on the part of the government and particularly the baladia in terms of introducing regulations and building codes that promote more culturally and environmentally sustainable designs. In fact there is an apparent disconnection between current regulations and people's aspirations towards their houses to meet their changing needs. Moreover, high real-estate prices make it more difficult to buy land, and this makes it even more difficult to use sustainable strategies such as vernacular elements especially with people's growing spatial requirements. Therefore, the paper recommends that the baladia immediately introduce sustainability mandates and enforce the standards on all buildings in Kuwait. Also, these sustainability regulations need to include incentivize homeowners to design and build sustainably. The incentives can be in the form of tax breaks or favorable rules allowing for more spacious homes. Many countries in the Middle East have had such programs in place for years and now the time has come for Kuwait to build more sustainable built environments.

(2) Importance of design-build collaboration: The project had a small team of construction supervisors, which included a civil engineer with no expertise in sustainable design or construction. Thus, the burden of developing sustainability fell completely on the architect. The experience was not only stressful but also very time consuming. Therefore, the project architect recommends for future endeavours to put together a professional design team that has extensive expertise in green buildings. Although more expensive, collaboration brings with it new ideas and strategies that further enhance the project.

(3) Catalogue for local green materials: Finally, it is rare to find local sustainable materials in Kuwait that are acceptable for contemporary living. In the past, houses were built of adobe and imported wood. Mud-brick construction has long since disappeared and is no longer suitable for Kuwait's built environment. Today, most of the green materials are imported from other countries and are expensive. The high cost makes it difficult to persuade architects and homeowners to use them instead of standard products. After construction was complete it was discovered that there are alternative regional sustainable materials and systems. For example, in Saudi Arabia there is a pioneering solar panels company. In the UAE there are also a few interesting studies conducted in Masdar City. Thus, a catalogue, booklet, or website providing information on local and regional green materials is an important tool for architects and is essential to realize a sustainable future for the Middle East.

\section{Conclusions}

The vernacular of any given region provides a rich precedent for knowledge, and therefore, taking inspiration from the past is necessary to direct people's sustainable aspirations for the future. Kuwait's "post oil" transformation created disunity between its past and present built environments, and as a result, the "cultural manifestations" (or traditional vernacular elements) have disappeared and lost their relationship with Kuwaiti culture. Although, some research highlighted how a few elements persisted through Kuwait's modern transformation [60] [61] [62], more research is necessary to understand these phenomena. As a result, this study intended to advance prior research to not replicate the past but learn from it by revisiting the principles behind the traditional vernacular. What appears to be needed is as Fathy said, "an appraisal of the conditions under which the traditional solutions are technically, environmentally, socially and economically valid, so that use can be made of this knowledge in appropriate situations" [63]. The design through research undertaking in this study upheld and developed that idea in an attempt to bridge the gap between theory and practice. Surely, the objective for this 
study has been achieved with regards to the process of design iteration, development, and construction, which provided valuable knowledge and building know-how. This data may be built upon and encourage researchers and designers to move towards sustainable design and development in Kuwait. The vision is not to nostalgically recreate the past, but to carry relevant aspects of its identity forward, expressing a contemporary sensitivity towards culture and the natural environment. A new architectural language is therefore necessary to gain inspiration from the principles and essence of the past, and to address the functional needs of the present, and to aspire to create built forms for a more sustainable future.

\section{Acknowledgments}

The project architect and author would like to send special appreciation and gratitude to his family; parents, wife, and children for their support and patience during the design-built project. A special thank you goes to ILLUMINATE design-built studio and their supervision team. And of course, we thank you to all the people who gave their time and energy to make this project a reality, sharing the commitment to make a more sustainable world for future generations.

\section{REFERENCES}

[1] U.N. "Fifth Assessment Report on Climate Change." IPCCIntergovernmental Panel on Climate Change. http://www.ipcc.ch/report/ar5/wg1/ (Retrieved date accessed on Oct. 2018).

[2] AFED. "Arab Forum for Environment and Development report, Survival Options: Ecological Footprints of Arab Countries," 2012 Global Footprint Network, www.wedocs.unep.org (Retrieved date accessed on 2015).

[3] AlWatan. "Kuwait: the first in world in water and electric consumption," AlWatan Newspaper, http://www.alwatan.k uwait.tt/homepage (Accessed May 14, 2013).

[4] AlHaroun, Y. "Contemporary Attitudes to Vernacular Elements in Kuwait's Domestic Built Environment: A Mixed Method Study," PhD Thesis. University of Sheffield, UK. 2015. http://etheses.whiterose.ac.uk/8096/

[5] UNEP. "Eco-development," UNEP/GC/80 United Nations Environment Programme. 1976.

[6] Duxbury, N. and Gillette, E. "Culture as a key dimension of sustainability," Creative city network of Canada, Centre for expertise of culture and community.2007.

[7] Throsby, D. "Linking cultural and ecological sustainability," The International Journal of Diversity in Organizations, Communities and Nations, Vol. 8(1), pp.15-20., 2008.

[8] Gleeson, B. and Low, N. "Cities as consumers of the world's environment," Consuming Cities. London, UK: Routledge. 2000,pp.6.,https://www.taylorfrancis.com/chapters/cities-co nsumers-world-environment-brendan-gleeson-nicholas-low/ e/10.4324/9780203984611-8
[9] Hawkes, J. "Culture as a fourth pillar of sustainability," Melbourne: Common ground. pp. 1-60, 2005.

[10] Rapoport, A. "House Form and Culture," New Jersey, NJ: Prentice-Hall Inc. 1969.

[11] Oliver, P. "Shelter and Society," London, UK: Barrie and Jenkins Ltd. 1969.

[12] Collins, P. "Changing Ideals in Modern Architecture," London, UK: Faber and Faber, 1965.

[13] Oliver, P. "Vernacular Know-How. In Vernacular Architecture: Ethnoscapes: Current Challenges," in the Environmental Social Sciences. Turan, M. (Eds.). Aldershot. 1990, pp.147-160

[14] Oliver. P. "Built to Meet Needs," Cultural Issues in Vernacular Architecture. Oxford, UK: Elsevier. 2006.

[15] Fathy, H. "Architecture for the Poor: An Experiment in Rural Egypt," 1969. $3^{\text {rd }}$ Edition. Chicago, IL: University of Chicago Press. 1973.

[16] Rapoport, A. "House Form and Culture," New Jersey, NJ: Prentice-Hall Inc.1969.

[17] Rapoport, A. "The Meaning of the Built Environment: A Non-Verbal Communication Approach," University of Arizona Press, 1982.

[18] Turan, M. "Vernacular Architecture," Ethnoscapes: Current Challenges in the Environmental Social Sciences. Aldershot. 1990.

[19] Richards, S. “'Vernacular' Accommodations: Wordplay in Contemporary traditional Architecture Theory," Architectural Research Quarterly, Vol. 16(1), 2012, pp. 3748.DOI: $10.1017 / \mathrm{S} 1359135512000279$

[20] Wright. F. “'Introduction'. Quoted in Frank Lloyd Wright on Architecture," ed. Frederick Gutheim. New York, NY: Grosset and Dunlap. 1941, pp.62.

[21] LeCorbusier. "The Four Routes," London, UK: Dennis Dobson Ltd. 1947, pp.135-6.

[22] Richardson, V. "New Vernacular Architecture," New York, NY: Watson Guptill Publications.2001.

[23] Lim, W. "Architecture, Art, Identity: Is There Life in Singapore After Tabula Rasa?," In Identity Research/Research Papers: Architecture and Identity. Volkswagen Stiftung and Berlin University Technology. 2004.

[24] Rudofsky, B. "Architecture Without Architects," Museum of Modem Art, New York. 1964.

[25] Alexander, C. Hirshen, S. Ishikawa, C. Coffin and S. Angel. "Houses Generated by Patterns," Center for Environmental Structure, Berkeley, CA:. 1969.

[26] Pearson, D. "Earth to Spirit - In search for natural architecture, Vernacular Wisdom," Gaia Books, 1994, pp.96.

[27] Oliver, P. “"Vernacular Know-How," In Vernacular Architecture: Ethnoscapes: Current Challenges' in the Environmental Social Sciences. Turan, M. (Eds.). Aldershot. 1990, pp.147-160.

[28] Misırlisoy, D. "New Designs in Historic Context: Starchitecture vs. Architectural Conservation Principles," Civil Engineering and Architecture, vol. 5, no. 6, pp. 207214, 2017. DOI: 10.13189/cea.2017.050602 
[29] Yaman Sokienah, "Aspects of Sustainability in the Design Elements of Traditional Jordanian Houses," Civil Engineering and Architecture, Vol. 8, No. 6, pp. 1194 - 1201, 2020. DOI: $10.13189 /$ cea.2020.080604

[30] AlHemaidi, W. "The metamorphosis of the urban fabric in an Arab - Muslim city: Riyadh, Saudi Arabia,” Journal of Housing and the Built Environment. Vol.16, 2001.pp. 179-201

[31] AlNaim, M. "Architecture and Culture: Critical Studies on Arab Architecture," Al Riyadh, Saudi Arabia: AlYamama Publishing Inc.2005.

[32] Saleh, M. "The integration of tradition and modernity: A search for an urban and architectural identity in Arriyadh, the capital of Saudi Arabia," Habitat International, Vol.22(4), 1998. pp.571-589.

[33] Taylor, T., Nikolopoulou, M., Mahdjoubi, L. and Cullen, N. "Vernacular architecture and contemporary design in Oman: Challenges in a changing climate," In: Detail Design in Architecture, Translating sustainable design into sustainable construction, Cardiff. 2009.

[34] AlSallal, K. AlRais, L. Bin Dalmouk, M. "Designing a sustainable house in the desert of Abu Dhabi," Renewable Energy. Vol.49, 2012. pp.80-84.

[35] AlHaroun, Y. "Contemporary Attitudes to Vernacular Elements in Kuwait's Domestic Built Environment: A Mixed Method Study," PhD Thesis. University of Sheffield, UK. 2015. http://etheses.whiterose.ac.uk/8096/

[36] Groat.L and Wang.D. "Architectural Research Methods," 2nd edition, Amsterdam, Boston: John Wiley \& Sons, 2013, pp.7.

[37] Frayling, C. "Research in art and design," R. Coll. Art Res. Pap. 1993, pp. 1-5.

[38] Binder, T. and Redström, J. "Exemplary Design Research. In Proceedings of the Wonderground," Design Research Society International Conference, Lisbon, Portugal 2006.

[39] Swann, C. Action "Research and the Practice of Design," Des. Issues18, pp.49-61. 2002.

[40] Zimmerman, J., Forlizzi, J., Evenson, S. "Research through Design as a Method for Interaction Design Research" in HCI. ACM Press: New York, NY, USA, 2007, pp. 493-502.

[41] (Zimmerman \& Forlizzi. "Research through design in HCI" in Ways of Knowing in HCI, 2014, pp.167-189.

[42] Zimmerman, J., Stolterman, E., Forlizzi, J. “An Analysis and Critique of Research through Design: Towards a Formalization of a Research Approach," ACM: New York, NY, USA, 2010 pp. 310-319.

[43] Toeters, M., Ten Bhömer, M., Bottenberg, E.,Tomico, O., Brinks, G. "Research through Design: A way to drive innovative solutions in the field of smart textiles," Adv. Sci. Technol. Vol.80, pp. 112-117, 2013.

[44] Verbeke. J. "Research by Design Is up and Running," Architecture \& Education Journal, Vol.110-19. pp.111, 2011.

[45] Fraser. M. "Design Research in Architecture," New edition, Burlington: Ashgate, 2012.pp.137.

[46] Barrett.E and Bolt.B. "Practice as Research: Approaches to Creative Arts Enquiry," I B Tauris \& Co. Ltd, 2010, pp.129-130.
[47] Nelson. R. "Practice as Research in the Arts: Principles, Protocols, Pedagogies, Resistances, Houndmills, Basingstoke,” New York: Palgrave Macmillan, 2013, pp.23.

[48] AlHaroun, Y. "Contemporary Attitudes to Vernacular Elements in Kuwait's Domestic Built Environment: A mixed Methods Study," PhD Thesis. University of Sheffield, UK. 2015. http://etheses.whiterose.ac.uk/8096/

[49] Shiber, S. "The Kuwaiti Urbanization; Documentation, Analysis, Critique. Al Madianah Al Kuwaitiyyah," Kuwait City, Kuwait Government Printing Press.1964.

[50] Rapoport, A. "House Form and Culture,” N.J., Prentice-Hall Inc.1969.

[51] Turner, J. "Housing by People: Towards Autonomy in the building environments," New York, Pantheon Books.1977.

[52] Shiber, S. "The Kuwaiti Urbanization; Documentation, Analysis, Critique. Al Madianah Al Kuwaitiyyah,” Kuwait City, Kuwait Government Printing Press.1964.

[53] AlJassar, M. "Constancy and change in contemporary Kuwait City: The socio-cultural dimensions of the Kuwaiti courtyard and Diwaniyya," PhD thesis. University of Wisconsin, 2009.

[54] AlHaroun, Y. "Contemporary Attitudes to Vernacular Elements in Kuwait's Domestic Built Environment: A mixed Method study," PhD Thesis. University of Sheffield, UK. 2015. http://etheses.whiterose.ac.uk/8096/

[55] AlHaroun, Y. "Perceptions of the Courtyard in Kuwait, between tradition and modernity," Journal of Arabian Studies, V.9, pp. 182-208, 2019. DOI: https://doi.org/10.1080/21534764.2019.1770422

[56] AlMumin, A. "Thermal Performance Prediction of Shaded Sunken Courtyard buildings in a Hot and Arid Climate," PhD Thesis. Texas A\&M University.1995.

[57] GreenSpec, “The UK Concrete Industry: Sustainable Construction Strategy", https://www.greenspec.co.uk/buildi ng-design/concrete-industry-sustainable-construction-strate gy-/ (Retrieved date accessed on April. 2021).

[58] Reis Pereira, M., Barara, T. "Bamboo as Sustainable Material Used in Design and Civil Construction: Species, Management, Characterization and Applications," Key Engineering Material, Vol.634, pp.339-350, 2014 DOI: https://doi.org/10.4028/www.scientific.net/KEM.634.339

[59] ADUPC, "Estidama: The Pearl Rating System," Abu Dhabi Urban Planning Council, Abu Dhabi.2010.

[60] AlHaroun, Y., AlAjmi, M. "Understanding socio-cultural spaces between the Hadhar and Badu houses in Kuwait," ARCH-net: International Journal of Architectural Research, Vol.12, Issue 3, pp. 68-89, 2018. DOI: http://dx.doi.org/10.26687/archnet-ijar.v12i3.1712

[61] AlHaroun, Y., "The Phenomenon of Apartments in the Kuwaiti House," Journal of Engineering Research, Vol. 8, Issue 2, pp. 1-24, 2019.

[62] AlJassar, M. "Constancy and change in contemporary Kuwait City: The socio-cultural dimensions of the Kuwaiti courtyard and Diwaniyya," $\mathrm{PhD}$ thesis. University of Wisconsin, 2009.

[63] Fathy, H. "Natural Energy and Vernacular Architecture: Principles and Examples with Reference to Hot Arid Climates," Chicago, University of Chicago Press. pp.200, 1986. 